\title{
Identifikasi Morfologi Haematopinus sp. pada Sapi Limousin Asal Karanganyar dan Sapi Fries Holland (FH) Asal Boyolali
}

\author{
Morphological Identification of \\ Haematopinus sp. in Limousin cows from \\ Karanganyar \\ and Fries Holland $(\mathrm{FH})$ cows from Boyolali
}

\author{
Aan Awaludin ${ }^{\# 1}$, Yudhi Ratna Nugraheni ${ }^{* 2}$, Kurniasih ${ }^{* * 3}$ \\ \# Produksi Ternak, Jurusan Peternakan, Politeknik Negeri Jember \\ Jalan Mastrip Kotak Pos 164 Jember \\ * Departemen Parasitologi, Fakultas Kedokteran Hewan, Universitas Gadjah Mada \\ *** Departemen Patologi, Fakultas Kedokteran Hewan, Universitas Gadjah Mada \\ ${ }^{1}$ aanawaludin@polije.ac.id/aanawaludin@gmail.com \\ ${ }^{2}$ yudhi.ratna.n@mail.ugm.ac.id/yudhiratnanugraheni@gmail.com \\ ${ }^{3}$ kurniasih_1951@yahoo.com
}

\begin{abstract}
Ectoparasitic infestation is one of the major animal health issues affecting on the livestock industry in many parts of the world. Haematopinus sp. is an ectoparasite that causes pediculosis (ptiriasis) in cattle, investing in large quantities causes itching and weight loss because it causes irritation, discomfort, and several studies explain that Haematopinus sp. can lead to decreased milk production and decreased quality of cow products. The objective of the study was to identify Haematopinus sp. in Limousin cows from Karanganyar and Fries Holland (FH) cows from Boyolali based on their morphology. Haematopinus sp. samples were taken from the tail end area, perineal vulva, ears and around the eyes of cows as much 5 - 10 tails of each 1 cow that was invested. The results of morphological identification were analyzed descriptively. Haematopinus sp. samples in Limousin cows from Karanganyar and Fries Holland (FH) cows from Boyolali was identified as Haematopinus quadripertusus.
\end{abstract}

Keywords : Ectoparasit, Haematopinus, Louse, Ptiriasis

\section{PENDAhuluan}

satu jenis hewan ternak yang memiliki arti penting bagi kehidupan manusia, terutama dari segi ekonomi karena dapat menghasilkan berbagai macam kebutuhan. Sapi dipelihara manusia dengan tujuan sebagai sumber daging, susu, tenaga kerja, dan kebutuhan lainnya. Ternak sapi menghasilkan sekitar 50\% kebutuhan daging di dunia, 95\% kebutuhan susu, dan kulitnya menghasilkan sekitar $85 \%$ kebutuhan kulit untuk sepatu. Dalam pemeliharaan sapi tidak lepas dari berbagai macam kendala, salah satunya adalah ektoparasit yang mengganggu perkembangan sapi (Pane, 1993).
Sapi

merupakan

salah

Infestasi ektoparasit merupakan salah satu masalah utama kesehatan hewan yang mempengaruhi industri peternakan di banyak bagian dunia (Hourigan, 1979). Ektoparasit termasuk kutu, tungau berperan penting dalam penularan penyakit tertentu (Loomis, 1986). Kutu diakui sebagai ektoparasit yang mempunyai potensi ancaman yang terbesar karena mampu mengakibatkan iritasi parah, alergi, dan toksikosis (Niyonzima and Kiltz, 1986).

Famili Haematopinidae merupakan ektoparasit yang paling sering menginfestasi sapi. Haematopinus euryternus telah dilaporkan 
menginfestasi sapi di daerah beriklim dingin sementara Haematopinus quadripertusus pada iklim tropis dan subtropis (Scofield et al., 2012). Haematopinus merupakan parasit terbesar dari keluarga kutu pada hewan domestik yang mempunyai semua siklus hidup pada induk semang, dan hanya bisa hidup beberapa jam di luar tubuh induk semang (Guimaraes et al., 2001).

Haematopinus sp. merupakan kutu pada hewan domestik dengan panjang sampai dengan 0,5 $\mathrm{cm}$, berwarna kuning atau abu-abu kecoklatan dengan garis-garis hitam pada masing-masing tepi, tidak mempunyai mata, serta memiliki tiga pasang kaki yang lebar dan pipih (Urquhart et al., 1987). Spiracle terdapat di bagian tepi dorsal dari mesothorak (Noble and Glenn, 1989). Kepala bagian belakang lebih lebar dibandingkan dengan bagian depan, berbentuk memanjang, dan menonjol di belakang antena serta dilengkapi dengan 5 ruas antena sedangkan bagian thorak luas dengan sternal plate di bagian bawah (Lapage, 1956).

Haematopinus sp. mempunyai mulut yang terdiri atas probosis halus dan kecil yang disebut sebagai haustelum dengan di bagian dalamnya dilengkapi gigi-gigi kecil yang diarahkan ke luar untuk ditancapkan pada kulit inangnya, tiga buah organ penusuk seperti jarum yang disebut stilet dapat dikeluarkan untuk menghisap darah dan menyuntikkan kelenjar ludah ke tubuh inang (Hadi dan Soviana 2000).

Meleney and Kim (1974), kunci identifikasi spesies dari Haematopinus sp. adalah pada bagian tepi abdomen mempunyai paratergite membulat atau kompak dengan 2 setae posterior, gonopod tidak meruncing di bagian posterior dari abdomen, sternal plate panjang lebih besar dari lebar di bagian bawah thorak, kepala panjang tidak ada batas di bagian ujung dan ditemukan pada ternak sapi, maka spesies ini mengarah ke Haematopinus euryternus atau mungkin Haematopinus quadripertusus. Haematopinus quadripertusus betina mempunyai panjang tubuh 3,42 - 4,75 mm dan jantan mempunyai panjang tubuh 3,04 - 3,52 $\mathrm{mm}$. Mempunyai dahi panjang, betina dilengkapi dengan processus anterolateral memanjang pada sternal plate thorax, saluran trakea abdominal (abdominal trachea thrunks) tebal, gonopod panjang dan sempit, subgenital plate median subrectangular lebih lebar dari panjangnya, abdominal tergit ke sembilan dengan processus anteromedial pendek dan tumpul. Kutu jantan subgenital plate dilengkapi 4 setae anterior ditemukan di negara tropis dan subtropis termasuk Amerika Selatan. Haematopinus euryternus berukuran lebih kecil yaitu 2,23 - 3,18 mm pada betina dan 1,99 - 2,7 mm pada jantan, dahi pendek, pada betina mempunyai processus anterolateral sternal plate tidak memanjang dan bulat, trakea abdominal tipis, gonopod pendek dan kompak, subgenital plate median subtrapezoid, lebih panjang dan melebar, tergit perut berjumlah sembilan dengan prosesus anteromedial memanjang dan lebih menonjol. Kutu jantan subgenital plate dilengkapi 6 setae anterior, ditemukan pada zona negara beriklim dingin.

\section{METODOLOGI \\ Lokasi Penelitian}

Sampel kutu sapi diambil dari beberapa sapi Limousin asal Kabupaten Karanganyar dan sapi Fries Holland (FH) asal Kabupaten Boyolali yang terindikasi menderita pedikulosis (ptiriasis). Sampel kutu diambil dari daerah ujung ekor, perineum vulva, telinga dan sekitar mata sapi dengan jumlah antara 5-10 ekor kutu untuk setiap 1 ekor sapi, yang dihitung sebagai satu sampel.

Penelitian dilaksanakan di beberapa tempat, yaitu di laboratorium Parasitologi Fakultas Kedokteran Hewan Universitas Gadjah Mada Yogyakarta untuk identifikasi morfologi kutu, laboratorium Hama Tanaman (Laboratorium Nematologi) Fakultas Pertanian Universitas Gadjah Mada Yogyakarta untuk pengukuran skala panjang, dan gambar kutu dengan menggunakan kamera lucida.

\section{Alat dan bahan}

Alat yang digunakan untuk pengambilan sampel kutu adalah sarung tangan karet, pinset, kertas label, dan microtube $2 \mathrm{ml}$. Alat yang digunakan untuk identifikasi morfologi kutu adalah slide glass, cover glass, cawan petri, jangka sorong (ketelitian 0,05 mm), kamera lucida, pensil, kertas HVS dan kertas kalkir.

Bahan yang digunakan dalam penelitian adalah etanol absolut dan minyak cengkeh.

\section{Metode Penelitian}

Sampel kutu diambil dari daerah ekor (terutama ujung ekor yang berambut), daerah sekitar perineum vulva, telinga, dan sekitar mata dari sapi yang menderita pedikulosis (ptiriasis) dengan menggunakan pinset, setiap satu ekor sapi diambil 5-10 ekor kutu kemudian dimasukkan dalam microtube $2 \mathrm{ml}$ berisi etanol absolut yang dihitung sebagai satu sampel kutu dan diberi label.

Identifikasi morfologi dilakukan dengan pengamatan makroskopis yang meliputi bagian tubuh, warna serta pengukuran panjang kutu dan lebar abdomen dengan menggunakan jangka sorong (ketelitian 0,05 mm). Sampel kemudian diamati dengan mikroskop binokuler. Pengamatan morfologi kutu meliputi morfologi dari caput, thorax, abdomen, dan extremitas. Gambar dan skala ukuran 
Aan Awaludin, Yudhi Ratna Nugraheni, Kurniasih. Identifikasi Morfologi Haematopinus sp. pada Sapi Limousin Asal Karanganyar dan Sapi Fries Holland (FH) Asal Boyolali

dari sampel dilakukan menggunakan mikroskop dengan kamera lusida perbesaran 4 x 10 kemudian gambaran bayangan dari objek sampel digambar ulang dengan menggunakan pensil pada kertas HVS di laboratorium Hama Tanaman (Laboratorium Nematologi) Fakultas Pertanian Universitas Gadjah Mada Yogyakarta yang kemudian dipindah ke kertas kalkir.

\section{HASIL DAN PEMBAHASAN}

Kutu sampel ditemukan dan diambil dari ujung ekor yang berambut, sekitar telinga, dan sekitar perineum vulva terutama bagian bawah. Pada area tersebut juga ditemukan nimfa dan telur kutu. Sampel kutu diambil dari sapi Limousin asal Kabupaten Karanganyar dan dari sapi Fries Holland (FH) asal Kabupaten Boyolali. Sampel kutu dewasa maupun nimfa dari setiap individu sapi diambil sebanyak $5-10$ ekor kutu dan dimasukkan ke microtube $2 \mathrm{ml}$ yang telah diisi etanol absolut kemudian diberi label.

\section{Identifikasi morfologi}

Pengamatan morfologi sampel kutu dari sapi Limousin dari Kabupaten Karanganyar (Gambar 1) dan Kabupaten Boyolali (Gambar 2) yaitu kutu sampel berwarna keabu-abuan, tubuh terbagi atas 3 bagian meliputi caput, thorax, dan abdomen dengan bentuk tubuh pipih dorso-ventral. Bagian kepala (caput) lebih kecil daripada bagian thorax, berbentuk sempit - runcing, mulut di bagian anterior kepala dengan tipe mulut penusukpenghisap, antena 2 buah dengan ruas antena sejumlah 5 ruas, tidak ditemukan bentukan mata, bagian thorax unsegmented dan terdapat 3 pasang kaki (proleg, mesoleg, dan metaleg) dengan masingmasing kaki terbagi atas 4 ruas (coxa, femur, tibia, tarsus), cakar 1 buah pada setiap kaki, tidak bersayap, abdomen segmented, paratergite membulat dengan ujung terdapat spiraculum dengan 2 buah rambut setae pada bagian posteriornya, saluran pernafasan (abdominal trakhea thrunks) terlihat tebal dan jelas, gonopod berbentuk panjang menyempit. Panjang tubuh rata-rata sampel kutu dari sapi Limousin Kabupaten Karanganyar (Tabel 1) adalah 4,625 $\mathrm{mm}$ (Tabel 1), sedangkan panjang tubuh rata-rata sampel kutu dari sapi Fries Holland (FH) asal Kabupaten Boyolali adalah 4,475 mm (Tabel 2).

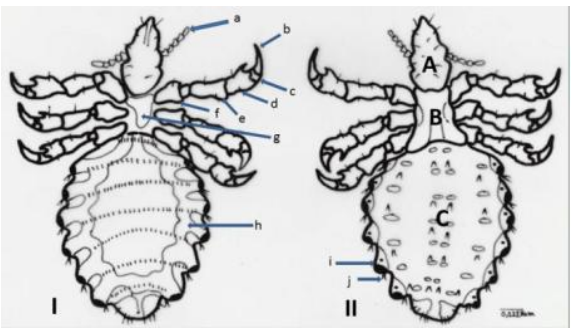

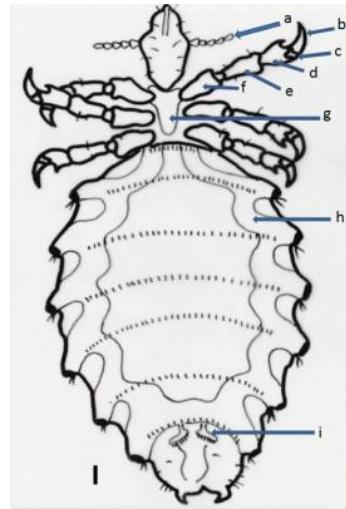

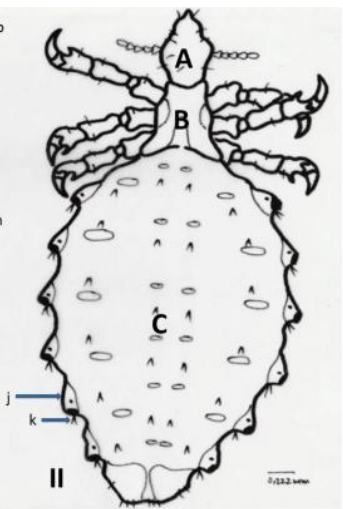

Gambar 1. Haematopinus sp. dari sapi Limousin Kabupaten Karanganyar (atas gambar Nimfa, bawah gambar kutu dewasa): I. Ventral (a. antenna, b. claw, c. tarsus, d. tibia, e. femur, f. coxa, g. sternal plate, h. abdominal tracheae thrunks, i. gonopod), II. Dorsal (A. Caput, B. Thorax, C. Abdomen, j. paratergite, k. setae). Scale bar : 0,222 mm.
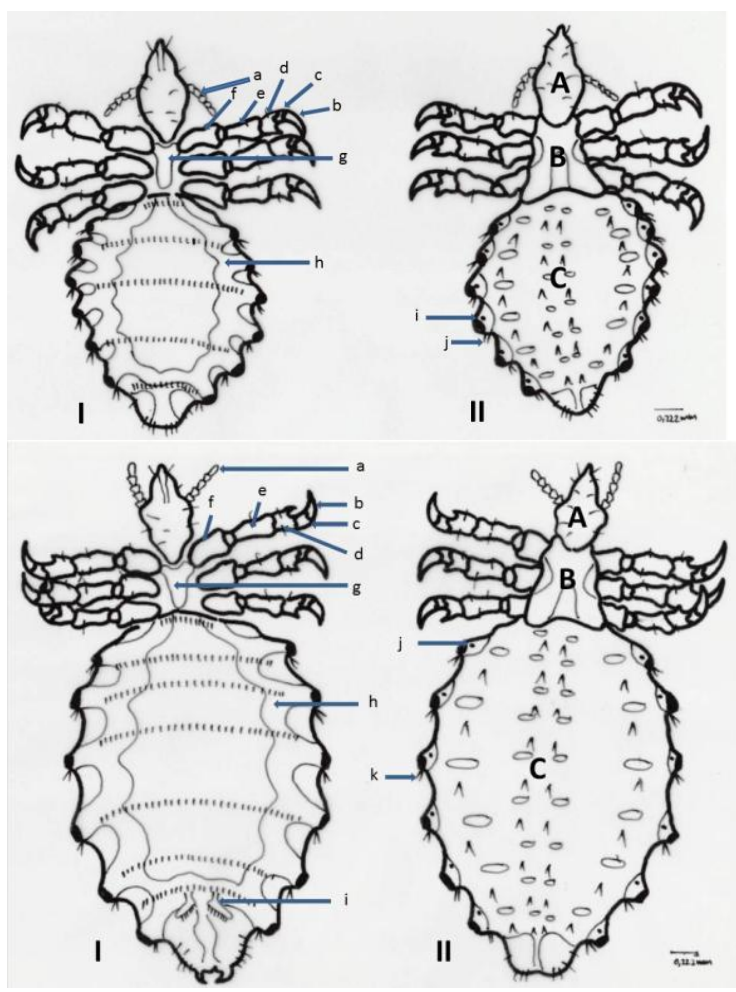

Gambar 1. Haematopinus sp. dari sapi Fries Holland (FH) Kabupaten Boyolali (atas gambar Nimfa, bawah gambar kutu dewasa): I. Ventral (a. antenna, b. claw, c. tarsus, d. tibia, e. femur, f. coxa, g. sternal plate, h. abdominal tracheae thrunks, i. gonopod), II. Dorsal (A. Caput, B. Thorax, C. Abdomen, j. paratergite, k. setae). Scale bar : 0,222 mm. 
TABEL. 1. SAMPEL KUTU DARI SAPI LIMOUSIN KABUPATEN KARANGANYAR

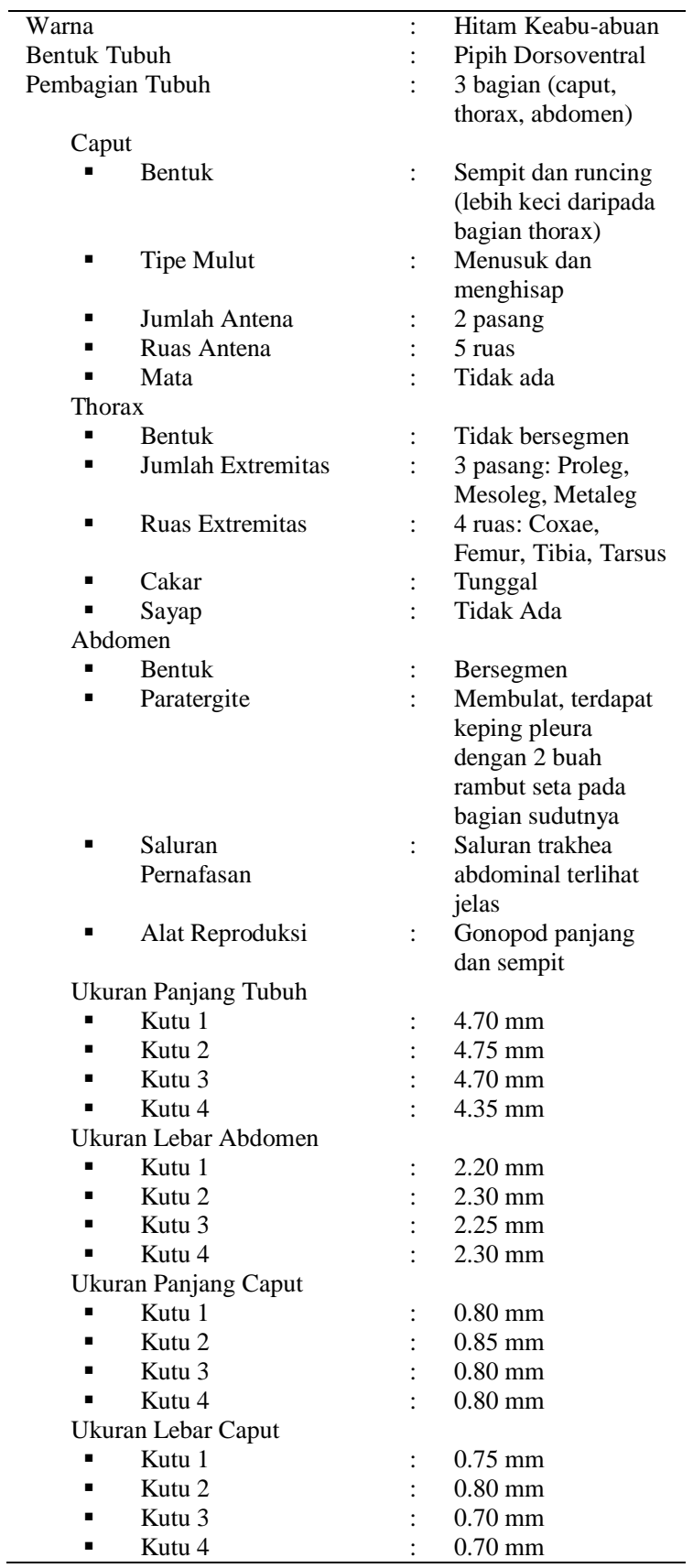

TABEL. 2. SAMPEL KUTU DARI SAPI FRIES HOLLAND (FH) KABUPATEN BOYOLALI

\begin{tabular}{|c|c|c|}
\hline \multirow{3}{*}{$\begin{array}{l}\text { Warna } \\
\text { Bentuk Tubuh } \\
\text { Pembagian Tubuh }\end{array}$} & : & Hitam Keabu-abuan \\
\hline & : & Pipih Dorsoventral \\
\hline & : & $\begin{array}{l}3 \text { bagian (caput, } \\
\text { thorax, abdomen) }\end{array}$ \\
\hline \multicolumn{3}{|l|}{ Caput } \\
\hline - $\quad$ Bentuk & : & $\begin{array}{l}\text { Sempit dan runcing } \\
\text { (lebih keci daripada } \\
\text { bagian thorax) }\end{array}$ \\
\hline - $\quad$ Tipe Mulut & : & $\begin{array}{l}\text { Menusuk } \\
\text { menghisap }\end{array}$ \\
\hline
\end{tabular}

\begin{tabular}{|c|c|c|c|}
\hline . & $\begin{array}{l}\text { Jumlah Antena } \\
\text { Ruas Antena } \\
\text { Mata }\end{array}$ & : & $\begin{array}{l}2 \text { pasang } \\
5 \text { ruas } \\
\text { Tidak ada }\end{array}$ \\
\hline \multicolumn{4}{|c|}{ Thorax } \\
\hline - & Bentuk & : & Tidak bersegmen \\
\hline 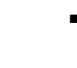 & Jumlah Extremitas & & $\begin{array}{l}3 \text { pasang: Proleg, } \\
\text { Mesoleg, Metaleg }\end{array}$ \\
\hline 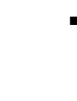 & Ruas Extremitas & : & $\begin{array}{l}4 \text { ruas: Coxae, } \\
\text { Femur, } \\
\text { Tarsus }\end{array}$ \\
\hline . & Cakar & : & Tunggal \\
\hline & Sayap & . & Tidak Ada \\
\hline \multicolumn{4}{|c|}{ Abdomen } \\
\hline . & Bentuk & : & Bersegmen \\
\hline & Paratergite & : & $\begin{array}{l}\text { Membulat, terdapat } \\
\text { keping }\end{array}$ \\
\hline - & Saluran Pernafasan & : & $\begin{array}{ll}\text { Saluran } & \text { trakhea } \\
\text { abdominal } & \text { terlihat } \\
\text { jelas } & \end{array}$ \\
\hline - & Alat Reproduksi & : & $\begin{array}{l}\text { Gonopod panjang } \\
\text { dan sempit }\end{array}$ \\
\hline \multicolumn{4}{|c|}{ Ukuran Panjang Tubuh } \\
\hline & Kutu 1 & : & $4.50 \mathrm{~mm}$ \\
\hline & Kutu 2 & : & $4.45 \mathrm{~mm}$ \\
\hline - & Kutu 3 & : & $4.45 \mathrm{~mm}$ \\
\hline & Kutu 4 & : & $4.50 \mathrm{~mm}$ \\
\hline \multicolumn{4}{|c|}{ Ukuran Lebar Abdomen } \\
\hline & Kutu 1 & : & $2.35 \mathrm{~mm}$ \\
\hline & Kutu 2 & : & $2.30 \mathrm{~mm}$ \\
\hline & Kutu 3 & : & $2.20 \mathrm{~mm}$ \\
\hline & Kutu 4 & : & $2.35 \mathrm{~mm}$ \\
\hline \multicolumn{4}{|c|}{ Ukuran Panjang Caput } \\
\hline & Kutu 1 & : & $0.75 \mathrm{~mm}$ \\
\hline & Kutu 2 & : & $0.70 \mathrm{~mm}$ \\
\hline & Kutu 3 & : & $0.70 \mathrm{~mm}$ \\
\hline - & Kutu 4 & : & $0.75 \mathrm{~mm}$ \\
\hline \multicolumn{4}{|c|}{ Ukuran Lebar Caput } \\
\hline & Kutu 1 & : & $0.70 \mathrm{~mm}$ \\
\hline 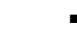 & Kutu 2 & : & $0.60 \mathrm{~mm}$ \\
\hline & Kutu 3 & : & $0.65 \mathrm{~mm}$ \\
\hline - & Kutu 4 & : & $0.70 \mathrm{~mm}$ \\
\hline
\end{tabular}

Warna tubuh kutu sampel dari sapi Limousin asal Kabupaten Karanganyar dan sapi Fries Holland (FH) asal Kabupaten Boyolali adalah hitam keabu-abuan dengan ukuran panjang tubuh rata-rata adalah $4,625 \mathrm{~mm}$ dan $4,475 \mathrm{~mm}$, tidak mempunyai mata, serta memiliki tiga pasang kaki yang lebar dan pipih dengan cakar tunggal disetiap kaki hasil tersebut menunjukkan bahwa kutu sampel yang dikoleksi adalah dari genus Haematopinus sp., sesuai dengan identifikasi Urquhart et al. (1987) dan Schmidt and Roberts (2000). Antena pada kepala sampel kutu berjumlah 2 dengan ruas sebanyak 5 ruas di setiap antena sesuai dengan identifikasi yang disebutkan Lapage (1956) untuk mengarah ke genus Haematopinus sp. Meleney and Kim (1974) menjelaskan tentang kunci identifikasi morfologi spesies dari Haematopinus sp., yaitu terdapat paratergite membulat atau kompak dengan 2 setae posterior, gonopod tidak meruncing di bagian posterior. Haematopinus quadripertusus mempunyai panjang tubuh $3,42-4,75 \mathrm{~mm}$ (betina) dan 3,04 - 3,52 $\mathrm{mm}$ (jantan), saluran trakea 
Aan Awaludin, Yudhi Ratna Nugraheni, Kurniasih. Identifikasi Morfologi Haematopinus sp. pada Sapi Limousin Asal Karanganyar dan Sapi Fries Holland (FH) Asal Boyolali

abdominal (abdominal trachea thrunks) tebal, gonopod panjang dan sempit. Haematopinus euryternus mempunyai ukuran panjang tubuh 2,23 $3,18 \mathrm{~mm}$ pada betina dan 1,99 - 2,7 mm pada ukuran jantan, trakea abdominal tipis, gonopod pendek dan kompak. Berdasarkan kunci identifikasi morfologi dari Haematopinus sp. tersebut maka sampel kutu dari sapi Limousin asal Kabupaten Karanganyar dan sapi Fries Holland (FH) asal Kabupaten Boyolali teridentifikasi sebagai spesies Haematopinus quadripertusus.

\section{KESIMPULAN DAN SARAN Kesimpulan}

Sampel kutu dari sapi Limousin asal Kabupaten Karanganyar dan sapi Fries Holland (FH) asal Kabupaten Boyolali adalah spesies Haematopinus quadripertusus.

\section{Saran}

Penelitian tentang identifikasi suatu spesies perlu dilakukan penambahan metode dengan Scanning Electron Microscope (SEM) untuk melihat kemungkinan ada tidaknya perbedaan ultrastruktur dan metode molekular untuk melihat jarak genetik dan kekerabatan (filogenetic tree) dari spesies yang diteliti.

\section{UCAPAN TERIMAKASIH}

Tim peneliti mengucapkan terimakasih sebesar-besarnya kepada Prof. drh. Kurniasih, M.VSc., Ph.D yang telah membimbing dan memberi dana penelitian secara pribadi sehingga penelitian ini bisa dilakukan. Ucapan terimakasih juga disampaikan kepada Dr. drh. R. Wisnu Nurcahyo atas semua bimbingan dan sarannya, departemen Parasitologi Fakultas Kedokteran Hewan dan laboratorium Hama Tanaman (Laboratorium Nematologi) Fakultas Pertanian Universitas Gadjah Mada Yogyakarta yang telah menyediakan tempat dan peralatan untuk kegiatan penelitian.

\section{DAFTAR PUSTAKA}

[1] Guimaraes, J. H, Tucc, E. C, Barros-Battesti, D. M. 2001. Ectoparasitos de Importância Veterinária. São Paulo: Plêiade; $213 \mathrm{p}$.

[2] Hadi, U.K. dan Saviana S. 2000. Ektoparasit: Pengenalan, Diagnosis dan Pengendaliannya. Fakultas Kedokteran Hewan, Institut Pertanian Bogor. Bogor. Hal.: 9-14.

[3] Hourrigan, J. L. 1979. Spread and detection of Psoroptic scabies of cattle in the United States. Journal of American Veterinary Association. 175:1278-1280.

[4] Lapage, G. 1956. Veterinary Parasitology. Oliver and Boyd Ltd. London. Hal : 377.
[5] Loomis, E. C. 1986. Ectoparasites of Cattle. Vet. [1]Clin. North America, 2: 299-321.

[6] Meleney, W.P. and Kim K. C. 1974. A Comparativestudy of cattle-infesting Haematopinus with redescription of $\mathrm{H}$. quadripertusus Fahrenholz,1916 (Anoplura : Haematopinidae)*. The journal of parasitology. 60 (3) : 507-522.

[7] Niyonzema, A. and Kiltz, H. H. 1986. Control of ticks and tick-borne diseases in Burundi. Australian Center for International Agricultural Research. 17:16-17.

[8] Noble, E.R. and Glenn, A. 1989. Parasitologi Biologi Parasit Hewan Edisi kelima. Gadjah Mada University Press. Yogyakarta. Hal : 386,717.

[9] Pane, I. 1993. Pemuliabiakan Ternak Sapi. Gramedia Pustaka Utama. Jakarta. Hal.1.

[10] Scofield, A, Campos, K. F, Melo da Silva A, M, Oliveira C, H, S, Barbosa, J. D, and Goes-Cavalcante G. 2012. Infestation by Haematopinus quadripertusus on cattle in São Domingos do Capim, state of Pará, Brazil. Rev. Bras. Parasitol. Vet., Jaboticabal, v. 21, n. 3, p. 315-318.

[11] Urquhart, G. M., J. Armour., J. L. Duncan, A. M. Dunn, F. W. Jennings. 1987. Veterinary Parasitology. Departement of Veterinary Parasitology, Faculty of Veterinary Medicine. University of Glasgow. Hal : 164-69. 